\title{
The brain decade in debate: I. Neurobiology of learning and memory
}

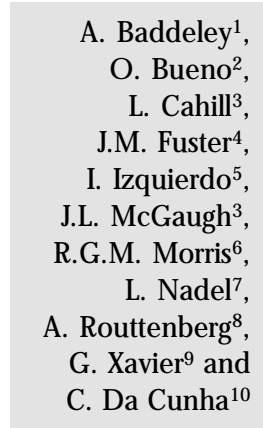

\section{Correspondence}

C. Da Cunha

Laboratório de Fisiologia e

Farmacologia do SNC

Departamento de Farmacologia,

UFPR

Caixa Postal 19.031

81531-990 Curitiba, PR

Brasil

E-mail: dacunha@ bio.ufpr.br

Publication supported by FAPESP. The names of the authors are presented in alphabetical order, except for the last one that corresponds to the symposium organizer.

Received May 16, 2000

Accepted June 21, 2000

\author{
${ }^{1}$ Department of Psychology, University of Bristol, Bristol, UK \\ ${ }^{2}$ Departamento de Psicobiologia, Universidade Federal de São Paulo, \\ São Paulo, SP, Brasil \\ ${ }^{3}$ Center for Neurobiology of Learning and Memory and Department of Neurobiology \\ and Behavior, U niversity of California, Irvine, CA, USA \\ ${ }^{4}$ Neuropsychiatric Institute, University of California, Los Angeles, CA, USA \\ ${ }^{5}$ Centro de Memória, Departamento de Bioquímica, Instituto de Biociências, \\ Universidade Federal do Rio Grande do Sul, Porto Alegre, RS, Brasil \\ ${ }^{6}$ Department of Neuroscience, The University of Edinburgh, Edinburgh, UK \\ ${ }^{7}$ Department of Psychology, U niversity of Arizona, Tucson, AZ, USA \\ ${ }^{8} \mathrm{~N}$ orthwestern University, Evanston, IL, USA \\ ${ }^{9}$ Departamento de Fisiologia, Instituto de Biociências, Universidade de São Paulo, \\ São Paulo, SP, Brasil \\ ${ }^{10}$ Laboratório de Fisiologia e Farmacologia do Sistema Nervoso Central, \\ Departamento de Farmacologia, Universidade Federal do Paraná, Curitiba, PR, Brasil
}

\section{Abstract}

This article is a transcription of an electronic symposium in which some active researchers were invited by the Brazilian Society for Neuroscience and Behavior (SBNeC) to discuss the last decade's advances in neurobiology of learning and memory. The way different parts of the brain are recruited during the storage of different kinds of memory (e.g., short-term $v s$ long-term memory, declarative $v s$ procedural memory) and even the property of these divisions were discussed. It was pointed out that the brain does not really store memories, but stores traces of information that are later used to create memories, not always expressing a completely veridical picture of the past experienced reality. To perform this process different parts of the brain act as important nodes of the neural network that encode, store and retrieve the information that will be used to create memories. Some of the brain regions are recognizably active during the activation of short-term working memory (e.g., prefrontal cortex), or the storage of information retrieved as long-term explicit memories (e.g., hippocampus and related cortical areas) or the modulation of the storage of memories related to emotional events (e.g., amygdala). This does not mean that there is a separate neural structure completely supporting the storage of each kind of memory but means that these memories critically depend on the functioning of these neural structures. The current view is that there is no sense in talking about hippocampusbased or amygdala-based memory since this implies that there is a oneto-one correspondence. The present question to be solved is how systems interact in memory. The pertinence of attributing a critical role to cellular processes like synaptic tagging and protein kinase A activation to explain the memory storage processes at the cellular level was also discussed.

\section{Key words}

- Memory

- Learning

- Hippocampus

- Prefrontal cortex

- Amygdala

- Memory systems

..................... 
The last decade of this millenium was considered as "The Brain Decade" because research in this field increased exponentially. Among the many subjects under study in neuroscience, the Neurobiology of Learning and Memory is considered by Steven Rose as the brain's Rosetta stone (1). The Rosetta stone was the key to the decoding of the Egyptian hieroglyphs, because it contained a text written in this and two other languages, Demotic Egyptian and Greek. As the Rosetta stone, the memory code, if it really exists, will be the key to the decoding of all brain functions. In order to discuss the scientific advances achieved by science in this field, the Brazilian Society of Neuroscience and Behavior (SBNeC) organized a virtual symposium held on March 10, 2000 in a chat site provided by the Conselho $\mathrm{Na}$ cional de Desenvolvimento Científico e Tecnológico $(\mathrm{CNPq})$. The present article was written based on the transcription of this symposium.

Gilberto Xavier: At the system level, how is the information encoded into and maintained in the different memory systems? Are there differences in the representation code for these systems? Are the retrieval mechanisms different?

Ivan Izquierdo: There are many differences among memories at the system level. First, and perhaps foremost, is the difference between short- and long-term processes, which are handled by different structures or the same structures with different timing. Second, working memory is a separate entity from all the others. Third, and very important, is declarative and procedural memory, which involves different systems. But I'm afraid this doesn't answer your question, does it?

Aryeh Routtemberg: We were just reviewing in class a short paper published in Nature (2). I think it is intriguing if shortterm and long-term memory are separate and the latter not dependent on the former. How- ever, why is the failure of short-term memory not a retrieval one?

Ivan Izquierdo: Better than that article is a recent review which came out in Behavioural Brain Research (3) a few months ago. The evidence that short-term memory failure is not a retrieval failure is that the retrieval of short-term memory is specifically affected by few treatments given, say, 10 min before the test, whereas the same treatments (protein kinase A (PKA) inhibitors, PD098058, etc.) given 0, 22 or 45 min before liquidate short-term memory.

Lynn Nadel: I haven't read the Nature paper, but the idea that short-term and longterm memory might be separate is well established. Ivan's latest comment points out two ways this could happen. I don't, however, find it very useful in the declarative/ procedural distinction, so perhaps someone could help me see what that adds.

Ivan Izquierdo: Lynn, you may be right. Bures recently presented a talk at a small symposium in his country called "How declarative can a rat's memory be?", in which he also argued that it is simply impossible to measure any memory in rodents or even bigger animals without measuring procedures.

Lynn Nadel: Ivan - What I think is important is to find principled ways of distinguishing memory systems, ones that go beyond the procedures used to measure them. I prefer to use the terms explicit and implicit because Schacter and others who coined them were clear that these were only operational definitions. It is important to detect differences such as "flexibility of use" and the like, in distinguishing memory systems. Elizabeth Warrington (4) showed about 30 years ago that you could get long-term memory in the absence of short-term memory, and that was the basis for her arguments against Brenda Milner's (5) consolidation view of hippocampal function.

Aryeh Routtemberg: Lynn - What I should have made clear is that short-term 
and long-term memory are independent and that Ivan showed... and there is not much on this as yet... that you can observe long-term memory in the absence of short-term memory. This is intriguing and gets to the heart of a new way of looking at multiple memory systems.

Ok, Lynn and Ivan... assuming that you have long-term memory in the absence of short-term memory demonstrated in rats and humans, what kind of neural/molecular mechanism do you envision operating to produce that consequence? Are there cases in the 'normal' individual where this occurs?

James McGaugh: Aryeh - I thought this was what Warrington and Shallice reported years ago (4).

Aryeh Routtemberg: Jim and Lynn Were these in normal subjects?

James McGaugh: Aryeh - No, in a patient. Not an often cited paper.

Lynn Nadel: Good question, Aryeh! Jim, what Warrington and Shallice (4) reported had to do with conduction aphasics, who indeed had poor short-term memory and good long-term memory. But the trick is they were talking about different "contents" (recall that their work predated the multiple memory systems idea).

Ivan Izquierdo: Depressed short-term memory in the presence of good long-term memory is characteristic of patients with delirium, and, to some extent, of depressive patients.

Lynn Nadel: That is very interesting - I would appreciate getting citations to those data later on. How many of you are aware of the recent report of decreased hippocampal volumes in chronically depressed people?

Ivan Izquierdo: What I just said is from psychiatry textbooks. At least that's where I've seen it mentioned.

Orlando Bueno: I believe that in humans it is necessary to distinguish between short-term memory of different contents (speech, visuo-spatial, as the phonological and visuo-spatial loops in Baddeley's mo- del) and short-term memory for semantically processed material. Short-term memory for speech and visuo-spatial material is very short in duration (seconds) and usually assessed by a span test (digit span, blocks of Corsi) (5). But I'm not sure about the present status of short-term memory (or recent memory, whatever name one gives to it) for meaningful material in the cognitive psychology literature. Anyway, I feel as a challenging matter for the next years a closer integration among cognitive psychology, neuropsychology and neurobiology of memory.

Aryeh Routtemberg: Ok, guys, so any thoughts on how short-term memory is liquidated (Ivan's term) while long-term memory remains solvent?

Gilberto Xavier: Aryeh, attention could be in the control of the process of sending information either to short-term memory or long-term memory. This would help to understand how information gets into implicit memory systems as well. What do you think?

Lynn Nadel: Aryeh - The problem of poor short-term memory/good long-term memory is only a problem if you think (a la Hebb) that the former is the necessary gateway to the latter. If they are handled by different systems, or even within the same system but by mechanisms that are not causally linked, then the result poses no particular problem.

James McGaugh: Unfortunately, Hebb was wrong about the causal link between short-term memory and long-term memory.

Lynn Nadel: Jim - What exactly do you mean by saying "short-term memory uses long-term memory"?

James McGaugh: Lynn - It seems obvious. Short-term memory must be about something. And it is always about things we already know about. Try your digit span. Try reading this. All in short-term memory immediately and all uses well-established longterm memory.

Gilberto Xavier: If we adopt the con- 
cept of working memory as proposed by Baddeley, the difficulties to understand the interaction between short-term and long-term memory diminish; apparently it becomes an attentional question, doesn't it?

Claudio Da Cunha: Ester Palacios, from Vitoria, Brazil, e-mailed us a message asking about the participation of the prefrontal cortex in the working memory processes.

Richard Morris: I'm not an appropriate person to comment on the role of the prefrontal cortex in working memory - maybe Alan Baddeley can say a word or two. Or else check out Paulesu's (6) review articles. Also Jonides (7).

Larry Cahill: Regarding the e-mailed question about the prefrontal cortex, I think the work of Petrides (8) and others has made it clear that while it is involved in various "manipulation" aspects of memory, it cannot be essential for memory per se as lesions have little or no effect. When a task involves some sort of manipulation of information, prefrontal cortex lesion effects seem to fall out, but not when simple retention of information per se is required.

Alan Baddeley (message e-mailed during the chat): As a cognitive psychologist I am pleased with the extent to which our analysis of human memory into separate but interrelated systems has proceeded and consolidated. There remain many controversies, but broadly speaking, most people would accept the usefulness of a distinction between long-term and working memory, and within working memory into separable visuospatial, verbal and executive components. In long-term memory there is now abundant evidence for separable implicit learning and memory systems, which differ from episodic memory and from semantic memory, although the relationship between these last two remains controversial. In terms of links with neurobiology, I think the development of neuroradiological methods has been very productive - initially much of the work was concerned with validating the methods and showing that there are parallels between scanning results and those obtained on the basis of cognitive studies and lesion approaches. We are now, I think, in a position to begin using scanning as a means of answering carefully targeted questions.

Challenges for the future? One major challenge is to ensure that we combine good questions with advancing scanning techniques - there is a temptation often to take a particular paradigm and simply label it with the name of some cognitive function. For example, in my own area, working memory is often regarded as synonymous with the nback task - a useful but complicated paradigm that is difficult to interpret theoretically. I think scanning and other electrophysiological methods offer a very useful tool for tackling the important but difficult issues of executive control. In the longer term, I have high hopes for our improved capacity to label neurotransmitters. As cognitive psychologists, we will need to be better at dealing with situations in which the modulation of a whole system is changed, rather than one in which a particular subcomponent is removed, for example by lesion. I expect that diseases that reflect deficits of this kind, perhaps schizophrenia and Alzheimer's disease for example, will prove theoretically as well as practically important. Finally, I hope that my many colleagues working on the neurobiological basis of memory will converge on some more wellestablished interpretations that can be mapped onto what we know of the cognitive psychology of memory. Sorry I am not able to take a more active part in what I am sure will be a lively and stimulating session. Best wishes, Alan Baddeley.

Joaquin Fuster: Dear Alan, I agree with you, the identification of different systems for memory has been an unquestionable advance. I am afraid, however, that this has led to misconceptions on the part of many cognitive neuroscientists. There is no greater problem in this field now than the tendency 
to allocate separate cognitive functions to separate neural structures - though each structure may participate differently and to a different degree in different functions. That tendency is largely the result of misinterpretations of lesion results and a hypertrophy of the concept of "module" which originated in sensory physiology. Both have led us to a new phrenology more or less legitimized by the scientific method. It is appropriate to dissect cognitive functions by experimental and cognitive psychology, as Aristotle would have undoubtedly approved. But our success in separating cognitive functions or contents (episodic memory, working memory, the "where", syntax of language, retrieval...) does not imply that there is a separate neural structure for each. We should certainly avoid the usage of relative differences (in tasks, areas, functional magnetic neuroimage activation - i.e., subtractions), as justifications for the categorical allocation of a particular cognitive function to a particular piece of cortex or cluster of cells. I address this comment to you, Alan, fully aware that I am preaching to the converted, for you have shown repeatedly serious misgivings about what I, not very originally, call the new phrenology. This gives me also the opportunity to share with you, who is the father of the concept of working memory, something quite amusing. After discovering "workingmemory cells" in the prefrontal cortex (9), I feel condemned to spend the rest of my life convincing people that working memory is not the only function of the prefrontal cortex and the prefrontal cortex is not the only cortex involved in working memory. Funny world! Cheers, Joaquin.

James McGaugh: Are there some broader issues to discuss? I think it is now extremely clear that short-term and longterm memory are independent processes. So, what are the implications? We need systems and mechanisms for both and both must be able to interact in microseconds. After all, short-term memory uses long-term memory.
The big problem in memory is not whether it is short or long (it is both) but how information is integrated in such a way that it can be retrieved and affect flexible performance. No use to store something if it cannot be adequately accessed. We have focused on the storage problem to a large degree because we have no hypotheses about how behavioral responses use stored information in a flexible way. Or does anyone have such hypotheses?

Lynn Nadel: Richard - Here's a thought I've had about a possible difference between frontal and hippocampal contributions to episodic memory. Imagine for a moment that the hippocampus rapidly establishes a "template" or trace that serves to link together various neocortical/limbic representations of all the things that happen in an episode. What is missing from this "static" ensemble is information about the sequence in which these things went together during the episode. This, I think, is what the frontal contribution could be, and why it seems so crucial in "working memory", which is nothing but a record of the sequence of recently experienced things.

Richard Morris: OK Lynn. But let's focus on your 'rapidly'. I'd like to add 'automatically' to that, rather than 'effortfully'. That is, the hippocampus is clocking away, recording events-in-scenes that are attended to, regardless of where a subject is directing his efforts with respect to encoding. I'm attracted to the idea of a distinction between 'automatic' components of episodic encoding (hippocampal) and 'effortful' components (the classical Tulving (10) list learning experiment).

James McGaugh: Richard and Lynn Do we know that the hippocampus proper is doing specific things in memory? Things, that is, that are not also done by other brain regions?

Lynn Nadel: As to some special role for the hippocampus - the latest data from remote memory studies seem to show that 
there are always subtle differences after hippocampal damage (11-13). There are also strong data indicating a necessary role for the hippocampus in some kinds of navigational situations, but I'm not sure that is a "memory" function per se.

Richard Morris: Only connect!!! Everything is combinatorial. Soon we will have an electronic journal called "Associative Molecular Biology"!!!! Mind you, if it is "Transgenic Associative Molecular Biology" maybe Aryeh won't want to be on the Editorial Board!! Sorry to lower the tone, folks back to serious stuff!!

James McGaugh: Richard (and Aryeh) Aryeh might want to be Senior Editor of such a journal. Why not?

Aryeh Routtemberg: Settle down, boys.

Lynn Nadel: Richard - OK. I suppose one could see the frontal role as relating to effortful encoding, as distinct from the automatic nature of hippocampal action, but which part of the system solves the sequence problem that I raised? This also applies to retrieval (Jim) - when we retrieve an episodic memory, how do we get the bits and pieces in the right temporal order?

Richard Morris: Lynn - sequences are tough. I'm still not sure how good animals are at sequences. The latest purely behavioral primate data on this question reveal competences, but not much more than that. It is an important issue, I concede, but is the ability to remember things accurately in sequence likely to be something for which there would have been a great deal of selective pressure in early mammalian evolution when the hippocampus and prefrontal lobe came along?

Lynn Nadel: Richard - A good point, but think about it more implicitly - even lowly animals need to get sequences right in order to get causality right - it matters if the conditioned stimulus precedes or follows the unconditioned stimulus, and animals are capable of remembering this sort of thing. I am particularly intrigued by the connection be- tween sequences and causal judgments...

Lynn Nadel: This forum gives me a chance to ask Larry and Jim something what are your current views on the impact of arousal/stress on memory - do you think that it is always positive, or is it U-shaped, or does it depend on what kind of memory one is talking about (e.g., amygdala-based, hippocampal-based, etc.)?

Larry Cahill: Lynn - I see no reason to think any brain structure or system operates in a non-inverted $U$ fashion in memory.

Ivan Izquierdo: Maybe it's late to raise such a potentially explosive point. But, what are the grounds to talk about "amygdalabased" as opposed to "hippocampal-based" memory? I, for one, don't see any.

James McGaugh: I agree with Ivan's comment.

Ivan Izquierdo: Jim - Thank you. It is a very basic point.

Lynn Nadel: Ivan - Excellent point - and we don't have enough time left to deal with it. I was hoping to get away with it.

Richard Morris: Amygdala-based memory. I'm rather disturbed about Larry Squire's exclusion of the amygdala-based memory from the class of representational types of memory (declarative in his terms) (14). The exclusion is based on the failure of amygdala lesions to affect delayed non-matching - but that is perhaps not the best of rocks on which to rest any theory just now. Surely we can 'declare' our emotional states? What is the basis for excluding amygdala-dependent memory from representational memory?

Larry Cahill: Richard - The failure of amygdala lesions to affect the delayed-nonmatching-to-sample task (a memory task used mainly for monkeys) fits nicely with the view that its primary function is to influence long-term memory consolidation for stresshormone releasing events.

James McGaugh: Richard - Amygdala dependent, in my view, does not mean emotional content $(15,16)$. Amygdala activity modulates memory of what to do in a water 
maze and where to go. It modifies memory of the size of a reward, it modifies memory of a story, etc. etc. I think it is a mistake to identify the amygdala with emotion. Emotion activates this region but the consequences need not be and usually are not memories of emotions.

Orlando Bueno: I think Jim has touched the point. The important thing is to find out how the structures and memory systems work together and so we would find that the amygdala participates in some way in declarative memory as an enhancer of memory $(17,18)$.

James McGaugh: Lynn - It is time for all of us to stop talking about "amygdala based" or "hippocampus based" as that implies that there is a one-to-one correspondence which, of course, is nonsense. What we need to know is how systems interact in memory. We have shown very clearly that amygdala activity regulates memory that involves hippocampal activity (i.e., explicit memory). Thus, the amygdala is very clearly part of the explicit memory system as are, no doubt, many other brain systems. There are no "hippocampal memories" and there are no "amygdala memories". If you think there are, direct me to the references supporting that view.

Lynn Nadel: Jim - Of course I agree with you - in fact I think we should dump the whole term "memory". What we store is information, and we later use that to "create" memories.

Richard Morris: Lynn - exactly! Traces are stored. Memories are created!

Ivan Izquierdo: Lynn - as to "creating" memories out of the information we store. Yes, maybe that is related to Squire's concept that consolidation takes years (14). I would, like most, restrict use of the word consolidation to the $6 \mathrm{~h}$ or so period in which memories are really set down after encoding. But I, again like most, would agree with Jim that we do form new memories on top of old ones, eventually modifying them and making up veritable lies. Every time we retrieve we probe into the complex and draw bits of one memory or other mixed with bits of other, usually older memories. The memories of many old people seem to be built like old cities (Jerusalem, Rome), tie over tie of older and older memories; you drill in, take up some material and the final result is often false. My mother, who otherwise had a good memory, confused events of my youth with those of her brother's; two persons she liked and who had a few things in common.

Lynn Nadel: Ivan - I agree that separating the short-lasting "consolidation" events from the longer-lasting (many years) things is crucial. Another topic for the next session...

Claudio Da Cunha: I agree with Ivan, but how are these traces of information coded? In my opinion, if we compare our knowledge about the neurobiology of learning and memory with the knowledge in genetics we are in a pre-double-helix stage: we cannot decode a brain state as traces of information useful to create memories. We cannot decode the information files! My guess is that with the refinement of the resolution of functional neuroimages this will be possible in the future.

Joaquin Fuster: In answer to Claudio's question, I suggest we should, at least in principle, accept the concept of network representation in the cortex and the distributed nature of all cognitive functions and types of memory (9), however difficult our experiments may thus become. I can see no better source of progress now than that position of principle.

Lynn Nadel: Claudio - I agree with your assessment of the problem, but not with your optimism about the resolution coming from the kind of functional neuroimaging available now (or in the foreseeable future). I think Joaquin touched on some of the problems with this approach.

Claudio Da Cunha: Indeed my optimism that we (or most probably the next generations) will discover a kind of key for decoding these traces of information that the 
brain uses to compose trace memories is not based only on functional neuroimages. Now, as Dr. Baddeley pointed out, this technique is becoming more and more powerful in resolution and proper to answer more specific questions that we could not solve with lesion/pharmacological approaches. I believe that someday we will find a way of using this or other techniques to decode a brain state in a sensible information useful to compose a memory trace.

Lynn Nadel: Richard - I would like to hear your current thoughts about whether properties evident at one level of analysis (e.g., cellular/molecular) show up at another level (e.g., systems) (19). An example might be the claim that the rapid plasticity evident in hippocampal long-term potentiation (LTP) (20) is also evident in the one-trial learning this system seems to be capable of $(21,22)$. Do you (and others) think this parallelism is an accident, or it will turn out to be a general feature?

Aryeh Routtemberg: Lynn - I grant you that conceptually, but given that there are many molecular mechanisms out there, what would be a plausible molecular/cellular scenario?

Richard Morris: Lynn - I have been intrigued by the possibility that the one-shot characteristic of LTP induction may be a physiological substrate of episodic or episodic-like memory. A twist is that I don't think LTP will, in general, last very long unless there is relevant protein sequestration and tag-protein interactions to stabilize these one-shot changes in synaptic efficacy that would underlie a 'record of experience' (23). A further twist is I don't understand the differential contributions of the hippocampus and prefrontal cortex to episodic memory - at encoding.

Claudio Da Cunha: I received an e-mail from Edson Cardia, from Brazil asking about the participation of cAMP response element binding (CREB) in the process of learning and memory. Would someone like to reply?
James McGaugh: Claudio - Evidence of CREB involvement in memory is interesting but not very informative as it is upstream from a large number of genes. Not a very precise tool, in my view (though, as you know we have worked on it here - as has Ivan's group).

Richard Morris: Ah Jim - but the specificity need not be at the level of the nucleus. That's what the synaptic tagging (23) idea is partly about. You can have a nuclear signal that is turned on by a variety of things, and can trigger via CREB (or other transcriptional activators) all sorts of genes. The proteins then synthesized will only be sequestered at activity-regulated sites that have the appropriate tags. I really like Harry Bito's (24) description of this problem as the "manyto-one' problem (synapses to the nucleus) and the 'one-to-many' problem (nucleus to the synapses).

Aryeh Routtemberg: Claudio - We have something like 100,000 genes, of which roughly $50 \%$ are regulatory. Of those 50,000 genes, one of them is CREB. We still need to know what the other 49,999 are doing. I am deeply concerned about the focus on CREB at different levels, but the most important one is that transcription factors never work in isolation but in a combinatorial way binding to recognition sites on the promoter and forming complex protein-DNA-protein complexes that lead to the initiation of transcription. The focus on CREB undermines any attempt to understand the cell biology of memory.

James McGaugh: Richard and Aryeh - I see no conflict in views. CREB clearly gives no synaptic specificity. But, Richard, how do we get a flexible behavioral read out from synaptic specificity? This is the silent question.

Ivan Izquierdo: As judged by the effects of PKA (25) and mitogen-activated protein kinase (MAPK) inhibitors (26), both sets of enzymes act at different moments and on different substrates to create short-term and 
long-term memory in the hippocampus. That would be a nice starting point: to look for those substrates. The bad news is that now it's known that PKA and the extracellular signal-regulated kinase system are truly enmeshed, cross-talk a lot with each other, and cross-talk with protein kinase $\mathrm{C}$ (PKC) a lot (27).

Aryeh Routtemberg: That's it! Parallel signal transduction processes, one leading to short-term memory retrieval the other kicking long-term memory into operation. Disruption of the former leads to the kind of result you have shown. Perhaps cross-talk is necessary, under normal conditions, for linking both signal transduction streams to longterm memory.

James McGaugh: Aryeh - Reasonable resolution. Independent and parallel in development. But, again, short-term memory must rapidly retrieve long-term memory in order to work.

Ivan Izquierdo: Back to a point raised by Aryeh. Yes, I suppose there must be cross-talk between short-term memory and long-term memory, as there must be between spatial and contextual components, declarative and procedural, visual and olfactory, etc. The thing is: who does the crosstalking and where? For short-term and longterm memory we do have indirect hints that it may take place at the PKA-MAPK-PKC mesh. In the hippocampus at least; perhaps also in the entorhinal cortex. Now, a major point is, who cross-talks the very early moments of memory, those in which, according to Richard, synapses are tagged, with the ensuing moments?

\section{Acknowledgments}

The SBNeC organizers are grateful to Hidevaldo Machado and Roberto Andreatini for the help with the organization of the chat and to Simone Alencar for technical assistance during the chat. The CNPq-Prossiga is also acknowledged for providing the chat web room.

\section{References}

1. Rose SPR (1991). Memory. The brain's Rosetta stone? Concepts in Neurosciences, 2: 43-64.

2. Izquierdo I, Barros DM, Mello e Souza T, De Souza MM, Izquierdo LA \& Medina J H (1998). Mechanisms for memory types differ. Nature, 393: 635-636.

3. Izquierdo I, Medina JH, Vianna MRM, Izquierdo LA \& Barros DM (1999). Separate mechanisms for short- and long-term memory. Behavioural Brain Research, 103: 1-11.

4. Warrington EK \& Shallice T (1969). The selective impairment of auditory verbal short-term memory. Brain, 92: 885-896.

5. Milner B (1971). Interhemispheric differences in the localization of psychological processes in man. British Medical Bulletin, 27: 272-277.

6. McGuire PK, Paulesu E, Frackowiak RS \& Frith CD (1996). Brain activity during stimulus independent thought. NeuroReport, 7: 2095-2099.

7. Smith EE \& J onides J (1999). Storage and executive processes in the frontal lobes.
Science, 283: 1657-1661.

8. Petrides M (1997). Visuo-motor conditional associative learning after frontal and temporal lesions in the human brain. Neuropsychologia, 35: 989-997.

9. Fuster J M (1995). Memory in the Cerebral Cortex. Massachusetts Institute of Technology Press, Cambridge, MA.

10. Tulving E (1983). Elements of Episodic Memory. Clarendon Press, Oxford.

11. Scoville WB \& Milner B (1957). Loss of recent memory after bilateral hippocampus lesions. J ournal of Neurology, Neurosurgery and Psychiatry, 20: 11-21.

12. Moscovitch $M$, Yaschyshyn $T$, Ziegler $M$ \& Nadel L (1999). Remote episodic memory and retrograde amnesia: Was Endel Tulving right all along? In: Tulving E (Editor), Memory, Consciousness and the Brain: The Tallinn Conference. Psychology Press, Philadelphia, 331-345.

13. Kubie J L, Sutherland RJ \& Muller RU (1999). Hippocampal lesions produce a temporally graded retrograde amnesia on a dry version of the Morris swimming task. Psychobiology, 27: 313-330.

14. Squire LR (1992). Memory and the hippocampus; a synthesis from findings with rats, monkeys and humans. Psychological Review, 99: 195-221.

15. Cahill L \& McGaugh J L (1998). Mechanisms of emotional arousal and lasting declarative memory. Trends in Neurosciences, 11: 294-299.

16. McGaugh J L (2000). Memory - A century of consolidation. Science, 287: 248-251.

17. Izquierdo I, Da Cunha C, Rosat R, Ferreira MBC, J enusalinsky D \& Medina J H (1992). Neurotransmitter receptors involved in memory processing by the amygdala, medial septum and hippocampus of rats. Behavioral and Neural Biology, 58: 16-25.

18. Da Cunha C, Levi De Stein ML, Wolfman C, Koya R, Izquierdo I \& MedinaJ H (1992). Effect of various training procedures in an elevated plus maze: Possible relation with brain regional levels of benzodiazepinelike molecules. Pharmacology, Biochemistry and Behavior, 43: 677-682.

19. Morris RGM, Anderson E, Lynch GS \& 
Baudry M (1986). Selective impairment of learning and blockade of long-term potentiation by an N-methyl-D-aspartate receptor antagonist, AP5. Nature, 297: 681-683.

20. Malenka RC \& Nicoll RA (1999). Longterm potentiation - a decade of progress? Science, 285: 1870-1874.

21. Carew TJ (1996). Molecular enhancement of memory formation. Neuron, 16: 5-8.

22. Xu L, Anwyl R \& Rowan MJ (1998). Spatial exploration induces a persistent reversal of long-term potentiation in rat hippocampus. Nature, 394: 891-894.
23. Frey U \& Morris RGM (1998). Synaptic tagging: Implications for late maintenance of hippocampal long-term potentiation. Trends in Neurosciences, 21: 181-187.

24. Bito $\mathrm{H}$ (1998). The role of calcium in activity-dependent neuronal gene regulation. Cell Calcium, 23: 143-150.

25. Bernabeu R, Bevilaqua L, Ardenghi $P$, Bromberg E, Schmitz PK, Bianchin M, Izquierdo I \& Medina JH (1997). Involvement of hippocampal D1/D5 receptorcAMP signaling pathways in a late memory consolidation phase of an aver- sively-motivated task in rats. Proceedings of the National Academy of Sciences, USA, 94: 1041-1046.

26. Atkins CM, Selcher J C, Petraitis JJ, Trzaskos J M \& Sweatt JD (1998). The MAPK cascade is required for mammalian associative learning. Nature Neurosciences, 1: 602-609.

27. Micheau J \& Riedel G (1999). Protein kinases: which is the memory molecule? Cellular and Molecular Life Sciences, 55: 534-548. 